\title{
Associação de Rhizoctonia solani Grupo de Anastomose 4 (AG-4 HGI e HGIII) à espécies de plantas invasoras de área de cultivo de batata
}

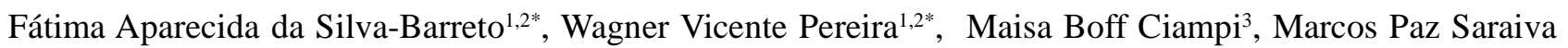 \\ Câmara ${ }^{4}$, Paulo Cezar Ceresini ${ }^{1,5}$
}

${ }^{1}$ UNESP - Universidade Estadual Paulista, Campus de Ilha Solteira, FEIS, Dept. Fitoss., Eng. Rural e Solos, Ilha Solteira, SP; ${ }^{2}$ USP - Campus de Piracicaba, ESALQ, Dept. Fitossanidade; atualmente alunos do Programa de Pós-Graduação em Fitopatologia; ${ }^{3}$ UNESP - Campus de Jaboticabal, FCAV, Programa de Pós-graduação em Genética e Melhoramento de Plantas, Jaboticabal, SP; ${ }^{4}$ UFRPE - Universidade Federal Rural de Pernambuco, Dept. Agronomia, Recife, PE; ${ }^{5}$ Swiss Federal Institute of Technology - ETHZ, Institute of Integrative Biology, LFW B28, 8092 Zurich, Switzerland, e-mail: paulo.ceresini@agrl.ethz.ch. *Os dois primeiros autores contribuíram de maneira igual para a execução desta pesquisa

Autor para Correspondência: Paulo Cezar Ceresini.

Data de chegada: 07/07/2008. Aceito para publicação em: 18/06/2009.

\section{RESUMO}

Silva-Barreto, F.A.S.; Pereira, W.V.; Ciampi, M.B.; Câmara, M.P.S.; Ceresini, P.C.. Associação de Rhizoctonia solani Grupo de Anastomose 4 (AG-4 HGI e HGIII) à espécies de plantas invasoras de área de cultivo de batata. Summa Phytopathologica, v.36, n.2, p.145-154, 2010.

Os grupos 3 e 4 de anastomose (AG-3 e AG-4) do fungo Rhizoctonia solani são importantes grupos associados à batata no mundo. No Brasil, o AG-3 é relatado afetando principalmente batata e fumo. Já o AG-4 causa perdas consideráveis em culturas de importância econômica, como a soja, o feijão e o amendoim, podendo ocorrer também em hortaliças como o espinafre, o pimentão, o brócolis, o tomate, a batata e frutíferas como o melão. Recentemente foi constatada, em Brasília-DF, a associação de $R$. solani a plantas invasoras em áreas de cultivo de batata. Entretanto, não há informação a respeito da etiologia do patógeno bem como do papel de espécies invasoras como outras hospedeiras no ciclo do patógeno. Objetivou-se com esse estudo caracterizar isolados de $R$. solani obtidos de batata e de outras três espécies de plantas invasoras associadas a áreas de cultivo da cultura: juá-de-capote [Nicandra physaloides (L.) Pers., Solanaceae], beldroega (Portulaca oleracea L., Portulacaceae), e caruru (Amaranthus deflexus L., Amaranthaceae). Foi confirmada a hipótese de que os isolados obtidos de $R$. solani de beldroega, caruru e juáde-capote pertencem ao grupo 4 de anastomose e são patogênicos à batata, exceto o isolado de beldroega. Estes isolados apresentaram patogenicidade cruzada às três espécies e também patogênicos à mariapretinha (Solanum americanum Mill.), uma outra espécie de Solanaceae invasora. A classificação dos isolados no grupo AG-4 HGI ou no grupo AG-4 HGIII (isolado de caruru) foi confirmada através de características culturais e moleculares (seqüenciamento da região ITS-5.8S do rDNA). Os resultados deste trabalho trazem implicações importantes para o manejo das podridões radiculares de Rhizoctonia em batata.

Palavras-chave adicionais: beldroega, caruru, juá-de-capote, maria-pretinha, patogenicidade cruzada.

\section{ABSTRACT}

Silva-Barreto, F.A.S.; Pereira, W.V.; Ciampi, M.B.; Câmara, M.P.S.; Ceresini, P.C.. Rhizoctonia solani anastomosis group 4 (AG-4 HGI and HGIII) associated with weed species from a potato cropping area. Summa Phytopathologica, v.36, n.2, p.145-154, 2010.

The anastomosis groups 3 and 4 (AG-3 and AG-4) of the fungus Rhizoctonia solani are important groups associated with potatoes worldwide. In Brazil, the AG-3 is reported affecting mainly potatoes and tobacco. The AG-4 cause considerable losses in crops of economic importance, such as soybean, beans and peanuts and may also occur in vegetables such as spinach, pepper, broccoli, tomatoes, potatoes and fruit such as melons. The association of $R$. solani with invasive plants was recently established in potato production areas from Brasília, DF. However, there is no information about the etiology of the pathogen as well as the role of invasive species as alternative hosts in the life cycle of the pathogen. The objective of this study was to characterize isolates of $R$. solani obtained from potatoes and three other invasive plant species associated with areas of potato production: Shoo-fly plant [Nicandra physaloides (L.) Pers.,
Solanaceae], pigweed (Portulaca oleracea L., Portulacaceae), and low-amaranth (Amaranthus deflexus L., Amaranthaceae). It was confirmed the hypothesis that the $R$. solani isolates obtained from pigweed, low-amaranth and Shoo-fly plant belong to the anastomosis group 4 and, except for the isolate from pigweed, are pathogenic to potatoes. These isolates were cross pathogencic to all the three weed species tested and also to American nightshade (Solanum americanum Mill.), another Solanaceae invasive of potato fields. The placement of the isolates in the group AG-4 HGI or in the group AG-4 HGIII (isolate from caruru) was confirmed by cultural and molecular characteristics (sequencing of the ITS-5.8S region of rDNA). The results of this study provide important implications for the management of the Rhizoctonia root rot in potatoes.

Keywords: pigweed, low-amaranth, Shoo-fly plant, American nightshade, cross pathogenicity 
O Basidiomiceto Rhizoctonia solani Kühn [fase anamórfica de Thanatephorus cucumeris (Frank) Donk] é importante patógeno associado à batata (Solanum tuberosum L) no mundo (3). O patógeno ocasiona cancro em hastes e estolões bem como a crosta-preta (black scurf) que é caracterizada pela produção maciça de escleródios do fungo aderidos firmemente à superfície do tubérculo de batata $(3,4)$. A maioria dos isolados de $R$. solani associados com tubérculos de batata ou outras partes da planta são do grupo de anastomose AG-3 (cerca de $73 \%$ de freqüência de ocorrência). Entretanto, isolados do AG-1, AG-2, tipo 1 (ao redor de 20,1\%) e 2, AG-4 e AG -5, também têm sido encontrados em plantas de batata (3). Isolados do AG-3 e AG-4 foram considerados mais agressivos em batata, enquanto isolados do AG-2-1 foram medianamente agressivos (3).

Com exceção do AG-3, acredita-se que raramente outros AGs podem formar escleródios em tubérculos (3). Já o AG-4 é considerado como principal agente de cancros em hastes e estolões (3, 4). Quando o fungo ataca brotações, causa retardamento da emergência e morte das plantas, resultando em menor estande, desenvolvimento irregular das plantas e conseqüente redução na produção (3). A associação do AG-3 e do AG-4 à batata no Brasil foi relatada pela primeira vez por Bolkan \& Ribeiro (1). Recentemente, além do AG-4 HGI e HGII, Rosa et al. (24) relataram também a associação do AG-7 à batata em áreas de cultivo de Ponta Grossa, PR. Entretanto, apenas os isolados do AG-4 HGI e HGII foram capazes de causar cancro na haste e estolões de batata, enquanto o AG-7 foi não patogênico (24).

O AG-3 é patógeno específico de solanáceas, sendo subdividido em dois subgrupos: AG-3 PT (que infecta batata, tomate e berinjela, causando doenças associadas ao sistema radicular) e AG-3 TB (que causa mancha foliar em fumo) $(26,28)$. Estes dois subgrupos diferem quanto à biologia, à patogenicidade, à epidemiologia e, também, geneticamente $(5,6,12,17)$. Já o AG-4 não é tão específico quanto o AG-3, podendo causar podridão de sementes, damping off de pré e de pós-emergência e, ocasionalmente, podridão de raízes em diversas culturas. O AG-4 é subdividido em AG-4 HGI, HGII e HGIII, sendo que todos os subgrupos já foram detectados atacando várias culturas de importância econômica no Brasil $(7,8,18)$. O fungo pertencente ao AG-4 causa perdas consideráveis à soja, ao feijão e ao amendoim $(7,8,10,11)$, podendo ocorrer também em hortaliças como espinafre, pimentão, brócolis, tomate e batata, e frutíferas como o melão (18).

Em termos da ecologia do fungo, tanto o AG-3 como o AG-4 são considerados patógenos que sobrevivem saprofiticamente em restos de cultura ou através de estruturas de resistência do tipo escleródios (3). Na ausência de plantas hospedeiras, R. solani pode sobreviver derivando seus nutrientes de restos orgânicos, como um saprófita do solo (9). A longevidade da população de $R$. solani AG-3 e AG-4 na batata é determinada pela densidade inicial de escleródios no início do período de rotação, condições de solo, e da atividade microbiana no solo $(16,21,23,25)$. Escleródios são relativamente resistentes à degradação no solo e podem sobreviver por vários anos na ausência da cultura da batata (25).

Opiniões diferem sobre qual fonte de inóculo é mais importante para o desenvolvimento das doenças causadas por Rhizoctonia em batata. Alguns relatos indicam que a presença de inóculo no solo é mais importante (16), enquanto outros sugerem que a presença do patógeno no tubérculo é de maior importância (15). Controvérsias a parte, o uso de rotação com culturas não hospedeiras é considerado o manejo mais adequado para reduzir a quantidade de inóculo de $R$. solani no solo. De forma complementar à rotação, a utilização de batata -semente livre do patógeno é considerada a forma mais importante para se evitar a introdução do patógeno numa área livre do patógeno ou após a adoção da rotação de culturas (3).

A rotação de culturas, como medida de controle da doença, pode reduzir o inóculo de isolados de $R$. solani AG-3 da batata no solo porque este $\mathrm{AG}$ é específico à solanáceas (28). O mesmo não pode ser afirmado para o AG-4, pois diversas culturas são hospedeiras deste AG $(7,8,10,11,18)$. Culturas suscetíveis a $R$. solani AG-4 não deveriam ser cultivadas mais que uma vez a cada três anos na mesma área, pois o inóculo do patógeno tende a aumentar a cada ano (21). Dessa forma, se o AG-4 é o mais freqüente numa determinada área, produtores de batata deveriam evitar rotações de curto-prazo de batata com feijão ou soja $(8,10)$. Entretanto, mesmo sob rotação de culturas, é possível que a densidade de inóculo de $R$. solani AG-3 ou AG-4 no solo não se reduza se os mesmos puderem infectar plantas invasoras suscetíveis que ocorrem nas áreas de cultivo.

Recentemente foi constatada, no Distrito Federal, a associação de $R$. solani com plantas invasoras em áreas de cultivo de batata. Entretanto, não há informação clara sobre a etiologia do patógeno bem como sobre o papel dessas espécies de plantas invasoras como outras hospedeiras no ciclo do patógeno. O conhecimento a respeito da importância de espécies invasoras como hospedeiros de $R$. solani em áreas de cultivo de batata pode ter implicações relevantes para o manejo das doenças causadas por Rhizoctonia em batata.

Objetivou-se com este estudo caracterizar isolados de $R$. solani obtidos de batata e de outras três espécies de plantas invasoras associadas a áreas de cultivo da cultura: beldroega (Portulaca oleracea L., Portulacaceae), caruru (Amaranthus deflexus L., Amaranthaceae) e juá-de-capote (Nicandra physaloides (L.) Pers., Solanaceae). Nossa hipótese é que os isolados obtidos de $R$. solani de beldroega, caruru e juá-de-capote pertençam aos grupos 3 ou 4 de anastomose (pela freqüência de ocorrência desses AGs na batata) e são patogênicos à batata e às demais espécies invasoras, inclusive à maria-pretinha (Solanum americanum Mill.), uma outra Solanaceae comum em campos de batata.

Para responder à questão sobre que AGs de $R$. solani estão associado à plantas invasoras de áreas de cultivo de batata, isolados do patógeno foram caracterizados através de: a) seqüenciamento da região ITS do DNA ribossomal; b) grupamento de anastomose; c) atributos culturais (taxa de crescimento micelial radial a 25 e $35^{\circ} \mathrm{C} \mathrm{e}$ curvas de crescimento em função da temperatura; necessidade de tiamina para crescimento); e d) patogenicidade cruzada de isolados de plantas invasoras à batata.

\section{MATERIAL E MÉTODOS}

Determinação das características citológicas e do grupamento de anastomose de isolados

Rhizoctonia solani. Os isolados de $R$. solani causadores de cancroda-haste em batata e tombamento em três espécies de plantas invasoras (caruru, beldroega e juá-de-capote) foram cedidos pelo Dr. Marcos Câmara da UFRPE, e os isolados padrões AG-2-2 IV, AG-3 e AG-4 HGI, pelo Dr. Nilton L. Souza da UNESP - Campus de Botucatu (Tabela 1).

O fungo $R$. solani é multinucleado, sendo o número médio de núcleos em células jovens utilizado como um critério importante para discriminar espécies (27). Para a caracterização da condição nuclear dos isolados, discos de micélio de $2 \mathrm{~mm}$ de diâmetro [obtidos de culturas em meio de batata-dextrose-ágar (BDA) acrescido de 
Tabela 1. Relação de isolados testes de grupos de anastomose de Rhizoctonia solani utilizados neste estudo para testar o grupamento de anastomose de isolados de Rhizoctonia solani, associados ao cancro-da-haste (da batata) e a tombamento (em plantas invasoras de áreas de cultivo de batata), mantidos na micoteca do Laboratório de Fitopatologia do Departamento de Fitossanidade da UNESP Campus de Ilha Solteira.

\begin{tabular}{|c|c|c|c|c|c|c|}
\hline Isolados & $\begin{array}{c}\text { Grupo de } \\
\text { Anastomose }\end{array}$ & $\begin{array}{l}\text { Código } \\
\text { original }\end{array}$ & Hospedeiro & Local & Ano & $\begin{array}{c}\text { Número de acesso da seqüência } \\
\text { no GenBank/NCBI }\end{array}$ \\
\hline \multirow{3}{*}{$\begin{array}{l}\text { Isolados } \\
\text { padrões }\end{array}$} & AG-2.2 IV & RI-64 ${ }^{\mathrm{a}}$ & Beterraba & Ohio, EUA & 1993 & AY270014 \\
\hline & AG-3 & $\mathrm{SCl} 24^{\mathrm{b}}$ & Batata & Alaska Fairbanks, EUA & - & AY 154319 \\
\hline & AG-4 HGI & $\mathrm{AH}-1^{\mathrm{a}}$ & Amendoim & Chiba, Japão & 1993 & AY 154307 \\
\hline \multirow{4}{*}{$\begin{array}{c}\text { Isolados de grupos } \\
\text { de anastomose } \\
\text { desconhecido }\end{array}$} & - & Rhs-BAT & Batata & Brasília, DF & 2002 & - \\
\hline & - & Rhs-BEL & Beldroega & ، & “ & - \\
\hline & - & Rhs-CAR & Caruru & “ & “ & - \\
\hline & - & Rhs-JUA & Juá-de-capote & “ & “ & - \\
\hline
\end{tabular}

Isolados cedidos ou coletados por: ' ${ }^{\text {L }}$. J. Herr, Ohio State University, Wooster, Ohio, EUA; ' D. Carling, University of Alaska, Alaska Fairbanks, EUA; ' M. Câmara, UFRPE, Recife, Pernambuco, Brasil

cloranfenicol (C) e estreptomicina (E) a 0,050g. $\mathrm{L}^{-1}$ (BDACE), crescidas por $48 \mathrm{~h}$ em estufa biológica] foram transferidos individualmente para lâminas de vidro contendo uma camada fina do meio de ágar-água (AA) a $1,5 \%$ e $1,5 \mathrm{~mL} / \mathrm{L}$ do corante de alimentos McCormick (13), incubados a $25^{\circ} \mathrm{C}$ por $18 \mathrm{~h}$ e observadas quanto ao número de núcleos por células utilizando-se corante nuclear Safranina O de Bandoni (sob microscopia de luz convencional) e DAPI (sob microscopia de fluorescência, com UV a $410 \mathrm{~nm}$ ) (14). Os testes para determinar a condição nuclear dos isolados foi delineado de forma inteiramente casualizada, com cinco repetições cada.

Para se determinar o grupamento de anastomose, os isolados de $R$. solani Rhs-BAT, Rhs-BEL, Rhs-CAR e Rhs-JUA e os padrões AG-3 e AG-4 HGI foram cultivados em BDACE por $48 \mathrm{~h}$ em estufa biológica; das margens dessas culturas se obteve discos de micélio para pareamento. Os isolados de $R$. solani de AG desconhecidos foram pareados com isolados padrões do AG-3 e do AG-4 HGI em lâmina de vidro contendo uma camada fina de AA a 1,5\% e 1,5 mL/L do corante de alimentos McCormick $(13,14)$ e examinados quanto às categorias de reação de anastomose entre pares de isolados. Os pareamentos foram incubados a $25^{\circ} \mathrm{C}$ por 18 horas. Os pareamentos foram delineados de forma inteiramente casualizada, com cinco repetições cada. As lâminas foram observadas em microscópio utilizando uma gota de $\mathrm{H}_{2} \mathrm{O}$ e sobrepondo-se uma lamínula de vidro. As categorias de reações de anastomoses de hifas foram examinadas de acordo com Carling (2).

\section{Clonagem de amplicons de PCR e seqüênciamento de bases da região ITS-5.8S do rDNA.}

A extração de DNA do fungo, a amplificação via PCR e o seqüênciamento foram realizado no Laboratório de Fitopatologia do Departamento de Produção Vegetal da Faculdade de Ciências Agronômicas, Campus de Botucatu, UNESP. Estes isolados foram incubados em meio de BDA (suplementado com estreptomicina a $0,050 \mathrm{~g} / \mathrm{L}$ ), e mantidos por 8 dias em estufa biológica a $25^{\circ} \mathrm{C}$, e transferidos para o meio de BD (batata-dextrose suplementado com estreptomicina). O micélio foi recuperado por filtração em filtro de papel Whatman, macerado em nitrogênio líquido e o DNA genômico total extraído de acordo com Kuramae-Izioka (22). A amplificação por PCR seqüênciamento da região ITS1-5.8S-ITS2 rDNA foi realizada segundo Fenille et al. (10) em termociclador marca PTC-100. Os produtos de PCR foram purificados usando-se coluna de MicroSpin S-400 (Amershan Pharmacia). Para sequiênciamento da região ITS do rDNA, foi utilizado o kit pré-preparado para ciclo de seqüênciamento baseado em química de corante terminador ("dye terminator cycle sequencing pre-mix kit") (Amershan Pharmacia). Setenta e cinco ng de DNA amplificados foram utilizados por reação e um $\mu \mathrm{M}$ de cada um dos iniciadores ITS4 ou ITS5 em reações independentes. Os produtos de seqüênciamento foram separados em gel de poliacrilamida a $6 \%$, utilizando-se seqüenciador automático PE Applied Biosystems ABI377.

Devido à condição predominante de heterocário no ciclo de vida de Rhizoctonia (4), é comum observar-se heterogeneidade em seqüências de DNA de amplicons de PCR não-clonados (5). Para separar alelos distintos da região ITS-5.8S do rDNA de um produto de PCR heterogêneo, o amplicon heterogêneo foi clonado no vetor PCR2.1TOPO® (Invitrogen, San Diego, CA, USA). Plasmídios recombinantes de Escherichia coli One Shot ${ }^{\circledR}$ DH5a ${ }^{\mathrm{TM}}-\mathrm{T} 1 \mathrm{R}$ (Invitrogen) foram extraídos de cada uma das amostras heterogêneas clonadas e purificadas usando-se QIAprep ${ }^{\mathrm{TM}}$ Spin Miniprep Kit (Qiagen). Primers para um dos múltiplos sitios de clonagem do vetor foram usados para reamplificação e seqüênciamento. As sequiências obtidas foram analisadas pelo programa Sequencher 4.6 (Gene Codes Corporation) para determinação de qualidade, alinhadas pelo programa computacional ClustalW (30) para a análise filogenética.

Estabelecimento de curvas de crescimento micelial radial em função da temperatura.

$\mathrm{O}$ estabelecimento de curvas de crescimento micelial radial de isolados de $R$. solani associados à batata, caruru, beldroega e juá-decapote, em função da temperatura, foi efetuado para determinação das temperaturas basais (mínimas, ótimas e máximas). Os isolados, foram cultivados por $48 \mathrm{~h}$ em placas de Petri de $90 \mathrm{~mm}$ de diâmetro contendo meio de cultura BDACE, em estufa incubadora a 10, 15, 20, 25, 30, 35 e $40^{\circ} \mathrm{C}$, sob ausência de luz. O inóculo foi constituído de um disco de micélio de sete mm de diâmetro obtido das margens de culturas crescidas em BDACE a $25^{\circ} \mathrm{C}$ por $48 \mathrm{~h}$, sob as mesmas condições de luz. Determinou-se, também, o crescimento dos isolados padrões AG-2.2 IV, AG-3 e AG-4 HGI nas mesmas condições. Após 48h de incubação, mediu-se o diâmetro médio das culturas para se determinar a taxa de crescimento micelial radial (TCMR), expressa em mm.dia ${ }^{-1}$. O experimento foi delineado de forma inteiramente casualizada, com cinco repetições.

Determinação da necessidade de tiamina para crescimento.

A necessidade de tiamina para crescimento micelial foi determinada utilizando meio basal de GASP descrito por Ogoshi \& Ui (20). O 
meio basal de GASP constitui-se de D-glicose, $10 \mathrm{~g}$; L-asparagina, $2 \mathrm{~g}$; $\mathrm{MgSO}_{4} .7 \mathrm{H}_{2} \mathrm{O}, 0,5 \mathrm{~g} ; \mathrm{KH}_{2} \mathrm{PO}_{4}, 1 \mathrm{~g} ; \mathrm{Fe}\left(\mathrm{NO}_{3}\right)_{3} .9 \mathrm{H}_{2} \mathrm{O}, 0,2 \mathrm{mg}$; $\mathrm{ZnSO}_{4} .7 \mathrm{H}_{2} \mathrm{O}, 0,2 \mathrm{mg} ; \mathrm{MnSO}_{4} \cdot 7 \mathrm{H}_{2} \mathrm{O}, 0,1 \mathrm{mg}$; água destilada e deionizada, $1000 \mathrm{~mL}$. O hidrocloreto de tiamina foi adicionado após a esterilização $\left(10^{-5} \mathrm{M}=3,4 \mathrm{mg} / \mathrm{L}\right)$. Culturas novas de cada isolado foram crescidas separadamente em meio GASP + 20g de ágar [GASP sólido (com pH corrigido de 4,7 para 7)], sem tiamina e incubados em estufa biológica a $25^{\circ} \mathrm{C} / 10$ dias sob ausência de luz. Foram incluídos os padrões AG-3 e AG-4 HGI (autotróficos para tiamina) bem como o AG-2-2 IV, auxotrófico.

Um disco de cultura, de sete mm de diâmetro, de cada isolado foi transferido para $50 \mathrm{~mL}$ de meio de GASP com ou sem $10^{-5} \mathrm{M}$ de hidrocloreto de tiamina em frasco Erlenmeyer de $250 \mathrm{~mL}$. Os frascos foram distribuídos em agitador horizontal e incubados por 14 dias à temperatura de $25^{\circ} \mathrm{C}$ a $120 \mathrm{RPM}$. Após esse período, a massa micelial de cada isolado foi separada do meio de cultura através de filtração a vácuo e seca em estufa a $65^{\circ} \mathrm{C}$ por $48 \mathrm{~h}$, para se determinar a massa micelial seca dos isolados. $\mathrm{O}$ experimento foi delineado de forma inteiramente casualizada, com cinco repetições.

Patogenicidade cruzada de isolados de Rhizoctonia solani AG-4 HGI à batata, beldroega, caruru, juá-de-capote e mariapretinha.

O teste de patogenicidade cruzada dos isolados obtidos de batata, caruru, beldroega e juá-de-capote, foi conduzido em casa de vegetação no Campus da UNESP de Ilha Solteira, SP. Incluiu-se, no teste, uma outra espécie de planta invasora de áreas de cultivo de batata, denominada maria-pretinha ( $S$. americanum). O solo utilizado foi o LATOSSOLO VERMELHO Distrófico típico argiloso, retirado de área não cultivada na Fazenda de Ensino e Pesquisa - FEP - UNESP - Campus de Ilha Solteira (UNESP-CISA). O solo, de classificação semelhante ao empregado no experimento anterior, foi esterilizado por fumigação com brometo de metila, por uma semana.

O inóculo para infestação do solo foi preparado cultivando-se os isolados de $R$. solani AG-4 HGI em arroz parboilizado esterilizado, por 7 dias, à $25^{\circ} \mathrm{C}$. Uma semana antes da semeadura, efetuou-se a infestação do solo utilizando-se grãos de arroz parboilizado colonizados pelos respectivos isolados na proporção de aproximadamente $25 \mathrm{~g}$ (cinco grãos) para cada vaso de 5,0 kg de solo. Após uma semana da infestação, procedeu-se o plantio e/ou semeadura da seguinte maneira: quatro mini-tubérculos de batata, 60 sementes de beldroega, 40 sementes de caruru, 15 sementes de juá-de-capote, ou 60 sementes de maria-pretinha para cada vaso. Os mini-tubérculos de batata "Atlantic", obtidos por cultura de tecido, foram adquiridos da empresa Solanex (São João da Boa Vista, SP). Os mini-tubérculos de batata e cada espécie de planta invasora foram plantados/semeados em 25 vasos, sendo cinco sem inóculo, e outros quatro grupos de cinco vasos inoculados com um dos isolados: Rhs-BAT, Rhs-BEL, Rhs-CAR ou Rhs-JUA.

As sementes de juá-de-capote tiveram a dormência quebrada através de tratamento em banho-maria à $60^{\circ} \mathrm{C}$ por $5 \mathrm{~min}$. $\mathrm{O}$ experimento foi irrigado diariamente com auxílio de proveta, mantendo sempre o solo na capacidade de campo. Foram feitas observações diárias para detectar emergência de plântulas e ocorrência de cancro em hastes de batata e de tombamento (damping-off) nas demais espécies, até o $28^{\circ}$ dia após o plantio e/ou semeadura. O experimento foi conduzido de acordo com o delineamento em blocos casualizados num esquema fatorial do tipo 5 x 5 (isolados do patógeno + testemunha x espécies de plantas), com cinco repetições para cada tratamento. O experimento foi repetido duas vezes.

\section{Análise dos dados.}

Para determinar as relações filogenéticas, aplicou-se análise de máxima verossimilhança (MV) utilizando-se o programa PAUP* 4.0b10 (29). Para a análise de ML, MODELTEST 3.7 (22) foi utilizado para se determinar o modelo de substituição de bases de DNA o qual mais se ajustou aos dados. A análise filogenética foi executada tratando todos os 615 caracteres (bases) com o mesmo peso e considerando inserções como dados perdidos. Deste total, 77 continham sítios variáveis entre os três AGs e 44 sítios dentro do AG4. Análise de bootstrap foi executada para se testar a significância estatística para cada ramo das árvore gerada pela análise de MV, com 100 pseudoreplicações com todos os caracteres re-amostrados em cada replicação, com adição casual de sequiências dos taxa por replicação e com opção de troca de ramificações fixada como TBR.

As curvas de crescimento radial médio em função da temperatura, bem como o requerimento de tiamina para crescimento micelial, foram determinados utilizando-se a média dos valores observados em cinco repetições. Os dados do experimento de patogenicidade cruzada foram submetidos à análise de variância pelo teste $F$ de Snedecor e ao teste de $t$ para contraste de médias. Mediu-se duas variáveis: a) Número de brotações ou plantas emergentes remanescentes e b) ASCPD (área sobre a curva de progresso da doença), medida com base na incidência de cancro e/ou de tombamentos acumulada ao longo do período (19). Análises de variância e contrastes de médias foram efetuadas usandose o pacote de sofware estatístico SAS (versão 9.1 do Sistema SAS para Windows; SAS Institute Inc., Cary, NC, USA).

\section{RESULTADOS E DISCUSSÃO}

No presente trabalho, quatro isolados de $R$. solani foram caracterizados quanto ao grupamento de anastomose, a atributos culturais e à patogenicidade cruzada à batata e plantas invasoras (beldroega, caruru, juá-de-capote e maria-pretinha).

Na caracterização citomorfológica e de grupamento de anastomose dos isolados de batata e de plantas invasoras, foram incluídos dois isolados padrões de $R$. solani: o AG-3 e o AG-4 HGI. Todos os quatro isolados testados são multinucleados, assim como os dois isolados padrões. Observou-se fusão "imperfeita" de hifas ou do tipo C2 [caracterizando anastomose de hifas entre isolados, como descrito por Carling et al. (2)] entre hifas dos isolados Rhs-BAT, Rhs-BEL, Rhs-CAR e Rhs-JUA com o AG-4 HGI, enquanto que nenhuma reação de anastomose foi observada entre estes isolados quando pareados com o AG-3.

Os isolados Rhs-BEL e Rhs-JUA formaram um único grupo filogenético com o isolado de batata Rhs-BAT, para o qual o relacionamento filogenético mais próximo ocorreu com o AG-4 HGI (Figura 1). Observou-se polimorfismos nas seqüências de DNA da região ITS-5.8S entre os haplotipos do isolado de batata e os de beldroega e juá. Já o isolado Rhs-CAR, formou um grupo filogenético distinto com o AG-4 HGIII. Com exceção do isolado Rhs-BEL, os demais apresentaram seqüências heterogenias da região ITS, típico da condição heterocariótica do fungo. Para inferir os alelos distintos foi necessário clonar os produtos de PCR. Os grupos AG2-2 IV e AG-3 PT foram utilizados para enraizamento da árvore filogenética.

Para se complementar o processo de identificação, recomenda-se caracterizar atributos culturais considerados particulares aos grupos de anastomose, tais como a temperatura ótima de crescimento e a necessidade de tiamina para o crescimento micelial (27). Foram 


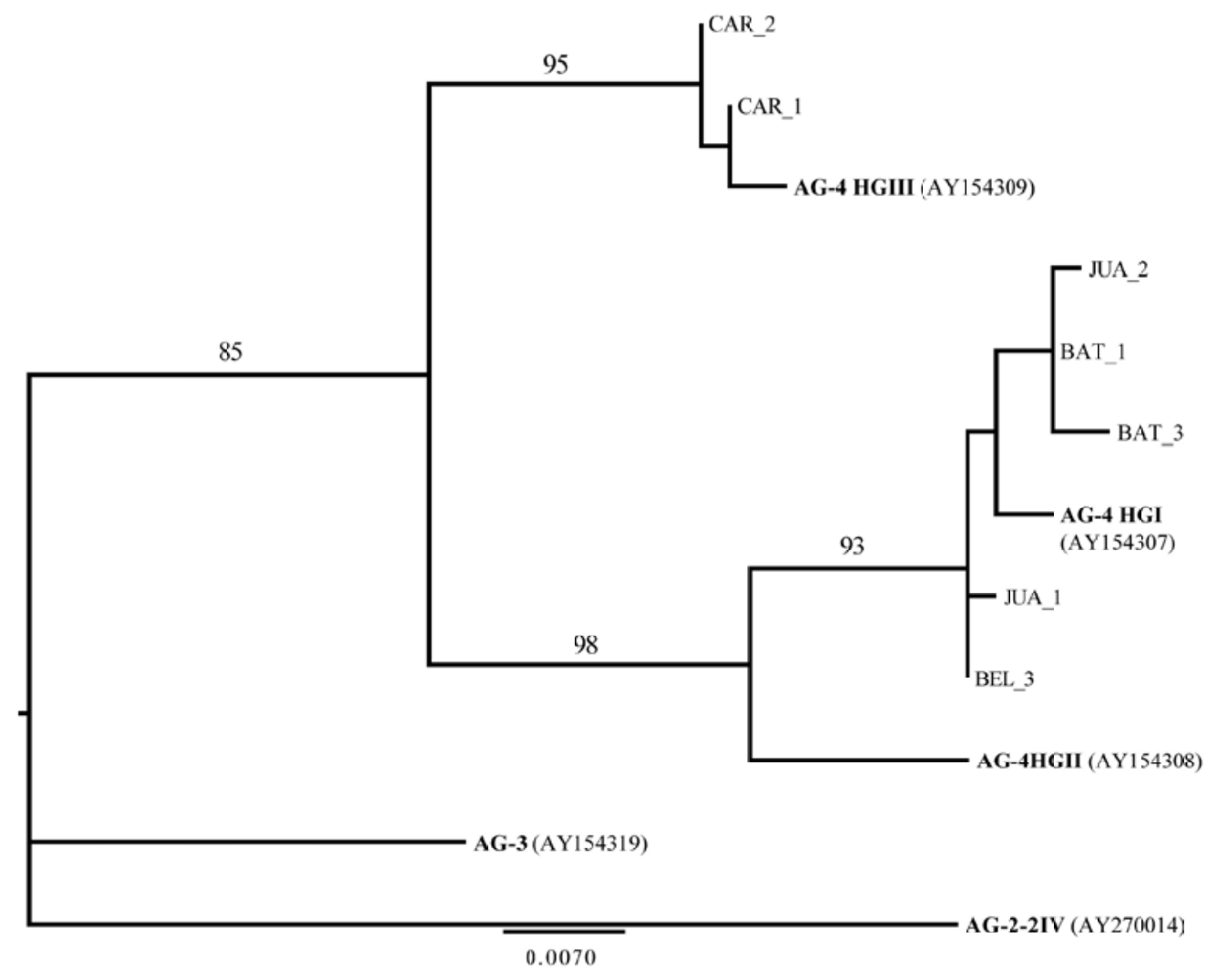

Figura 1. Árvore de máxima verossimilhança (MV) baseada no modelo HKY de evolução de bases de DNA. O valor de MV para a respectiva árvore foi de 1439,93. Acima de alguns ramos da árvore são apresentados os valores relativos à significância estatística através de análise de "bootstrap" das árvores geradas por análise de máxima verossimilhança (MV). Estes valores são expressos em percentual relativo à 100 pseudo-replicações. Por exemplo, 93\% das 100 árvores de ML geradas por pseudo-replicações dos dados apresentaram ramo que agrupa todos os haplótipos dos isolados de Rhizoctonia solani de batata (BAT), da beldroega (BEL) e de juá-de-capote (JUA) com o AG-4 HGI; 95\% das árvores pseudo-replicadas agrupam os haplótipos dos isolado de caruru (CAR) com o AG-4 HGIII. As relações filogenéticas foram construídas utilizando-se sequiências de DNA da região ITS-5.8S do rDNA contendo um total de 615 pares de bases. A barra acima indica número de substituições / sítio. A árvore foi enraizada usando seqüências da região ITS do AG-2-2 IV e do AG-3. Os taxa são identificados pelo código do isolado e/ou o código da seqüência obtida do GenBank®/NCBI. A descrição dos isolados de $R$. solani encontra-se apresentada na Tabela 1

observadas diferenças nas curvas de crescimento dos isolados AG-2.2 IV, AG-3 e AG-4 HGI (Tabela 2, Figura 2). A temperatura ótima para crescimento destes isolados foi de $25^{\circ} \mathrm{C}$. As temperaturas mínimas foram de $10^{\circ} \mathrm{C}$ para os isolados AG-2.2 IV e AG-3, e de $15^{\circ} \mathrm{C}$ para o AG 4 HGI. As temperaturas máximas foram de $30^{\circ} \mathrm{C}$ para o isolado AG-3 e de $35^{\circ} \mathrm{C}$ para os isolados AG-2.2 IV e AG 4 HGI. Em termos gerais, os isolados Rhs-BAT, Rhs-BEL, Rhs-CAR e Rhs-JUA apresentaram maior similaridade no padrão de crescimento micelial, em função da temperatura, com o grupo AG-4 HGI. Entretanto, observou-se diferença entre isolados. A temperatura ótima variou entre 25-30 ${ }^{\circ} \mathrm{C}$; a mínima foi de $10^{\circ} \mathrm{C}$ para Rhs-BAT, Rhs-CAR e Rhs-JUA e $15^{\circ} \mathrm{C}$ para $\mathrm{Rhs}-\mathrm{BEL}$; a temperatura máxima foi de $35^{\circ} \mathrm{C}$ para todos os isolados testados (Figura 2).

Quanto à necessidade de tiamina para crescimento micelial, observou-se que os isolados Rhs-BAT, Rhs-BEL, Rhs-CAR, RhsJUA e o padrão AG-4 HGI apresentaram crescimento micelial tanto na presença como na ausência de tiamina (Tabela 2). A razão B/A entre o crescimento na ausência (B) e na presença de tiamina (B) desses isolados foi inferior a 1,5 , sendo assim caracterizados como autotróficos para tiamina (20). O isolado padrão AG-3 foi também caracterizado como autotrófico para tiamina (razão $\mathrm{B} / \mathrm{A}=0,4$ ), entretanto apresentou crescimento relativo inferior a todos os demais isolados. Já o padrão AG-2-2 IV não apresentou crescimento na ausência de tiamina (razão
$\mathrm{B} / \mathrm{A}=18.9$ ), sendo caracterizado como auxotrófico para tiamina (Tabela 2).

Com o teste de patogenicidade cruzada, pode-se constatar que os isolados de $R$. solani AG-4 HGI utilizados neste trabalho foram patogênicos à batata e às plantas invasoras beldroega, caruru e jua-decapote (Tabela 3), observando-se sintomas de cancro em hastes e/ou tombamento das plantas em quaisquer das combinações de inóculo versus planta hospedeiras testadas (Figura 3). Na batata, não se observou diferença entre os isolados Rhs-BAT, Rhs-CAR e Rhs-JUA quanto ao nível acumulado de incidência de cancro de hastes ou tombamento (medido através da ASCPD). A única exceção foi o isolado Rhs-BEL, que não foi patogênico à batata durante o período de até 28 dias após a semeadura (Tabela 3, Figura 4).

A brotação de ramos de batata foi observada após cinco dias do plantio dos minitubérculos. No tratamento testemunha, detectou-se o máximo de 6,4 brotações por vaso contendo quatro minitubérculos, após 30 dias do plantio. Nenhum sinal de cancro em hastes ou tombamento de brotações foi detectado no tratamento testemunha. A infestação do solo com isolados de R.solani AG-4 reduziu o número de brotações para cerca de 4,0 a 5,0/vaso, entretanto não se detectou diferença significativa entre tratamentos quanto à brotação (Tabela 3 ). Os sintomas de cancro no colo das hastes de batata só foram observados no $26^{\circ}$ dia após o plantio em solo infestado. 
Tabela 2. Temperaturas basais e necessidade de tiamina para crescimento micelial apresentada por isolados padrões de grupos de anastomose de Rhizoctonia solani e dos isolados de arroz e soja associados à queima da bainha do arroz ou à mela da soja.

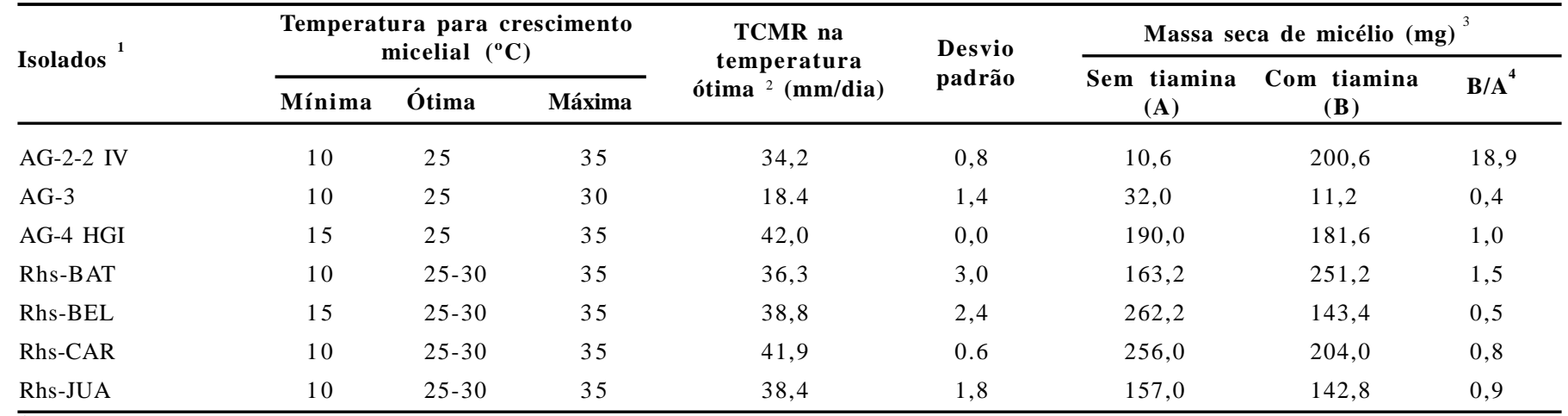

${ }_{2}^{1}$ Informação sobre os isolados utilizados encontra-se disponível na Tabela 1;

TCMR = taxa de crescimento micelial radial de isolados crescidos em meio de BDACE, por 48h de incubação. Média de cinco repetições. As curvas de crescimento micelial encontram-se na Figura 2;

${ }^{3}$ Isolados cultivados em meio de GASP com $\mathrm{pH}$ corrigido para 7 (suplementado ou não com $10^{-5} \mathrm{M}$ de hidrocloreto de tiamina), a $25^{\circ} \mathrm{C}$, por 19 dias, sob ausência de luz. O inóculo foi constituído de um disco de micélio obtido das margens de culturas crescidas em meio de GASP+A a $25^{\circ} \mathrm{C}$, por 10 dias, sob ausência de luz. Massa seca determinada após secagem em estufa, a $65^{\circ} \mathrm{C} / 48 \mathrm{~h}$, Média de cinco repetições;

${ }^{4}$ Valores inferiores a 1,5 para a razão B/A são indicativos de que os isolados são autotróficos para tiamina (20).
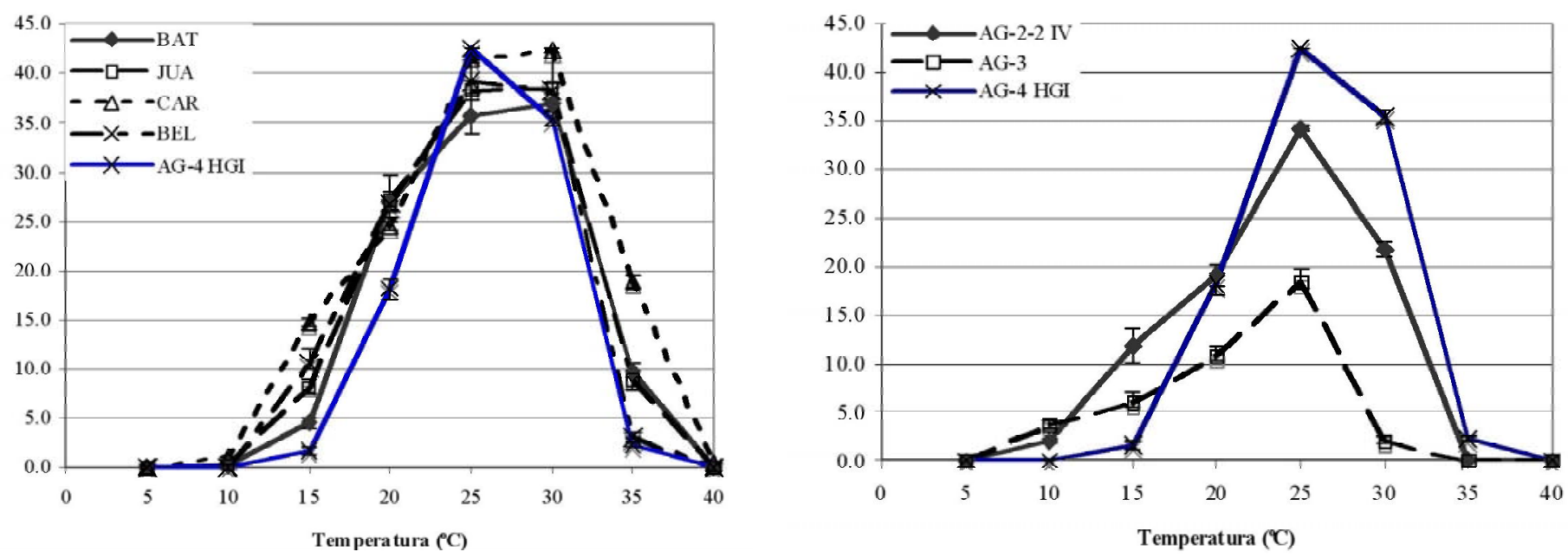

Figura 2. Curvas de crescimento micelial radial ( $\mathrm{mm} / \mathrm{dia})$ de isolados de Rhizoctonia solani da batata, de plantas invasoras de áreas de cultivo de batata, e de isolados padrões pertencentes aos grupos de anastomose AG-2-2 IV, AG-3 e AG-4 HGI, em meio de BDACE, após 48h de incubação. Média de cinco repetições. As barras indicam o erro padrão da média

Uma média de 45,2 plantas de beldroega emergiram no tratamento testemunha (sem infestação com o patógeno), no $30^{\circ}$ dia após a semeadura (Figura 4). Não se detectou tombamento de plantas no tratamento testemunha. Sob condições de solo infestado, o isolado Rhs-caruru promoveu a maior incidência de tombamentos e a menor emergência de plantas. Apenas cerca de cinco plantas remanescentes foram detectadas após 30 dias da infestação do solo (Tabela 3). Além de tombamento de pós emergência, todos os isolados de $R$. solani AG4 (HGI e HGIII) proporcionaram também a ocorrência de tombamento de pré- emergência, evidenciado pela diferença entre o número de plantas de beldroega emergidas no tratamento testemunha em comparação com os demais tratamentos de infestação do solo pelo patógeno.

No período de 30 dias, em média 31 plantas de caruru emergiram no tratamento testemunha e nenhum tombamento de plantas foi detectado (Tabela 3, Figura 4). Sob condições de solo infestado com $R$. solani AG-4, os três isolados de $R$. solani AG-4 HGI e o isolado do AG-4 HGIII (Rhs-CAR) promoveram incidência semelhante de tombamento pós-emergência de plantas de caruru, não sendo observada diferença significativa entre as ASCPD acumuladas (Tabela 3 ). Entretanto, observou-se que o isolado Rhs-CAR foi o mais agressivo, promovendo também tombamento de pré-emergência. O máximo de 5,8 plantas emergiram do tratamento solo infestado com Rhs-CAR, enquanto 15,2 a 18,4 plantas emergiram nos demais tratamentos.

O máximo de cerca de 10 plantas de juá-de-capote emergiram após 30 dias de semeadura em solo não infestado com o patógeno, onde nenhum tombamento foi detectado (Tabela 3, Figura 4). De forma geral, os isolados Rhs-BAT, Rhs-CAR e Rhs-JUA foram estatisticamente semelhantes em termos de incidência acumulada de tombamento pós-emergência. Não houve diferença significativa entre tratamentos considerando a amergência de plantas (Tabela 3).

Com relação à maria-pretinha, de maneira geral, as sementes apresentaram alta capacidade de germinação, com média de 55,6 plantas emergidas no tratamento testemunha, aos 30 dias após a semeadura (Tabela 3 , Figura 4). Não houve diferença significativa entre isolados quando ao nível acumulado de incidência (ASCPD) de tombamentos (Tabela 3). 
Tabela 3. Patogenicidade cruzada de isolados de Rhizoctonia solani AG-4 HGI e HGIII à batata e à plantas invasoras de áreas de cultivo da cultura

\begin{tabular}{|c|c|c|c|c|c|}
\hline \multirow[t]{2}{*}{ Tratamento $^{1}$} & \multicolumn{5}{|c|}{ ASCPD (\%.dia) ${ }^{2}$} \\
\hline & Batata & BeldroegaŹ & Caruru & Jut-de-capote & Maria-pretinha \\
\hline Rhs-BAT & 0,24 & $9,10 \mathrm{ab}$ & 7,07 & 4,96 & 0,33 \\
\hline Rhs-CAR & 2,18 & $18,53 \mathrm{a}$ & 11,98 & 4,26 & 1,29 \\
\hline Rhs-JUA & 0,96 & $4,62 \mathrm{~b}$ & 8,56 & 1,77 & 1,46 \\
\hline \multirow[t]{3}{*}{$P$} & 0,2674 & 0,0407 & 0.0666 & 0,1766 & 0,2053 \\
\hline & \multicolumn{5}{|c|}{ Plantas emergidas remanescentes } \\
\hline & Batata & BeldroegaŹ & Caruru & Juł-de-capote & Maria-pretinha \\
\hline Rhs-JUA & 4,0 & $16,6 \mathrm{~b}$ & $15,2 \mathrm{~b}$ & 5,0 & 34,4 bc \\
\hline Testemunha $\mathrm{n}<\mathrm{o}$ inoculada & 6,4 & $45,2 \mathrm{a}$ & $31,0 \mathrm{a}$ & 9,2 & $55,6 \mathrm{a}$ \\
\hline$F$ tratamentos $^{3}$ & $2.30^{\mathrm{NS}}$ & $25,10 * *$ & $22,80^{* *}$ & $2,56^{\mathrm{NS}}$ & $4,53^{*}$ \\
\hline$P$ & 0,1038 & 0,0001 & 0.0001 & 0,0790 & 0,0123 \\
\hline
\end{tabular}

${ }^{1}$ Inóculo preparado cultivando-se os isolados em arroz parboilizado esterilizado; o solo foi infestado transferindo-se cerca de $25 \mathrm{~g}$ (cinco graos) de arroz colonizado pelo fungo; plantas cultivadas sob condição de casa de vegetação; o isolado Rhs-CAR foi caracterizado como AG-4 HGIII e os demais como AG$4 \mathrm{HGI} ;{ }^{2}$ Area sob a curva de progresso da doença, medida pela acumulo da incidência no período de 30 dias de avaliação; ${ }^{3}$ Para efeito de análise estatística, tratamentos com valores absolutos igual a zero, por exemplo a testemunha não inoculada foram excluídos. Experimento delineado em blocos casualizados, com cinco repetições; Análise de variância através do teste $F$ de Snedecor; **, * significativo a $1 \%$ ou a $5 \%$ de probabilidade, respectivamente; ${ }^{\text {NS }}$ não significativo; médias seguidas pela mesma letra (nas colunas) são semelhantes entre si, pelo teste $t$ a $5 \%$.

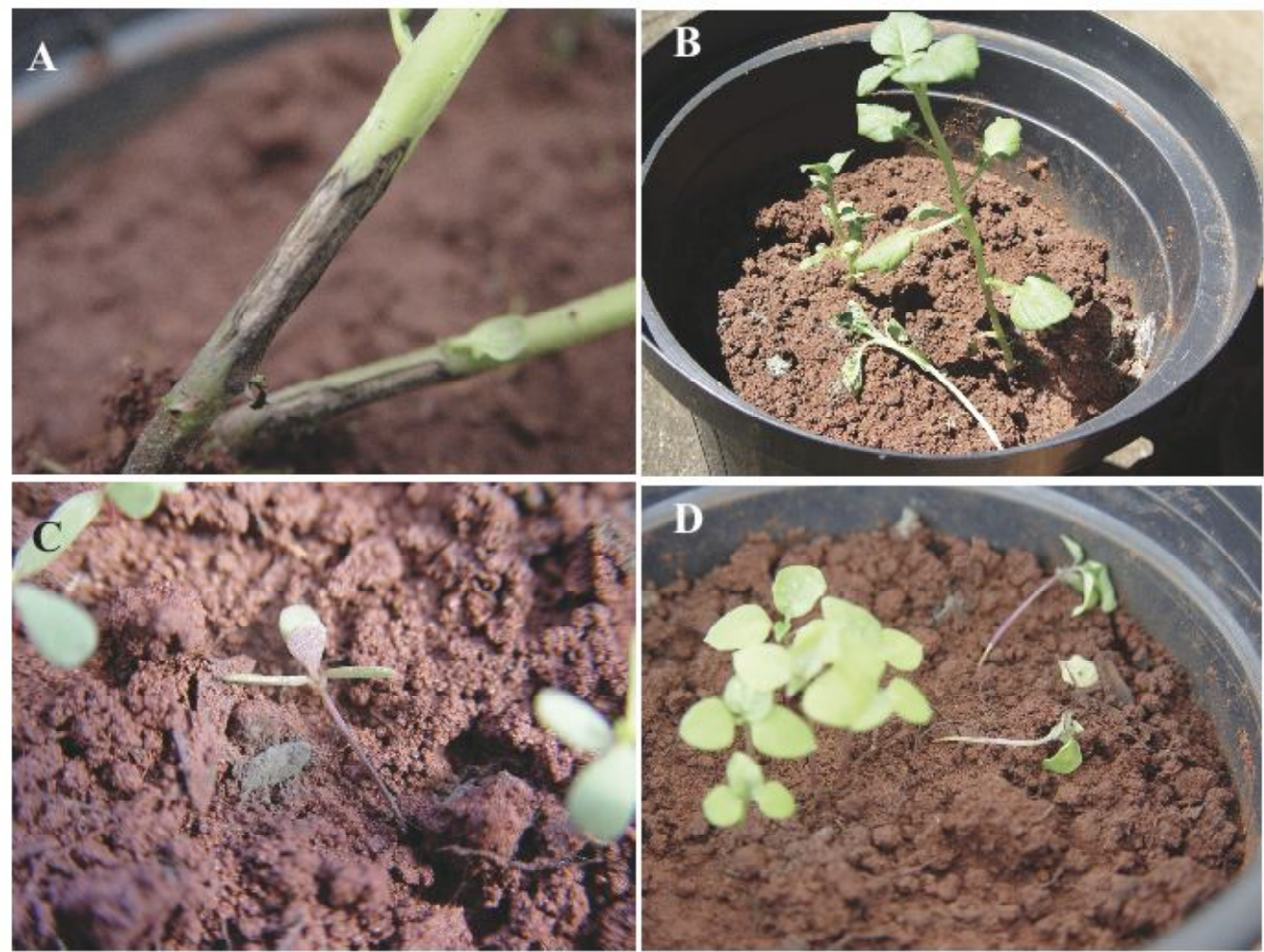

Figura 3. Patogenicidade de isolados de Rhizoctonia solani AG-4 HGI ou HGIII à batata, à beldroega e ao juá-de-capote. A. Sintomas de cancro do colo em plantas de batata "IAC 18" inoculada com o isolado Rhs-BAT (AG-4 HGI); B. Tombamento de brotações de batata inoculada com o isolado Rhs-CAR (AG4 HGIII); C. Tombamento de plântulas de beldroega causado pelo isolado Rhs-JUA (AG-4 HGI); e D. Tombamento de plântulas de juá-de-capote causado pelo isolado de Rhs-CAR 

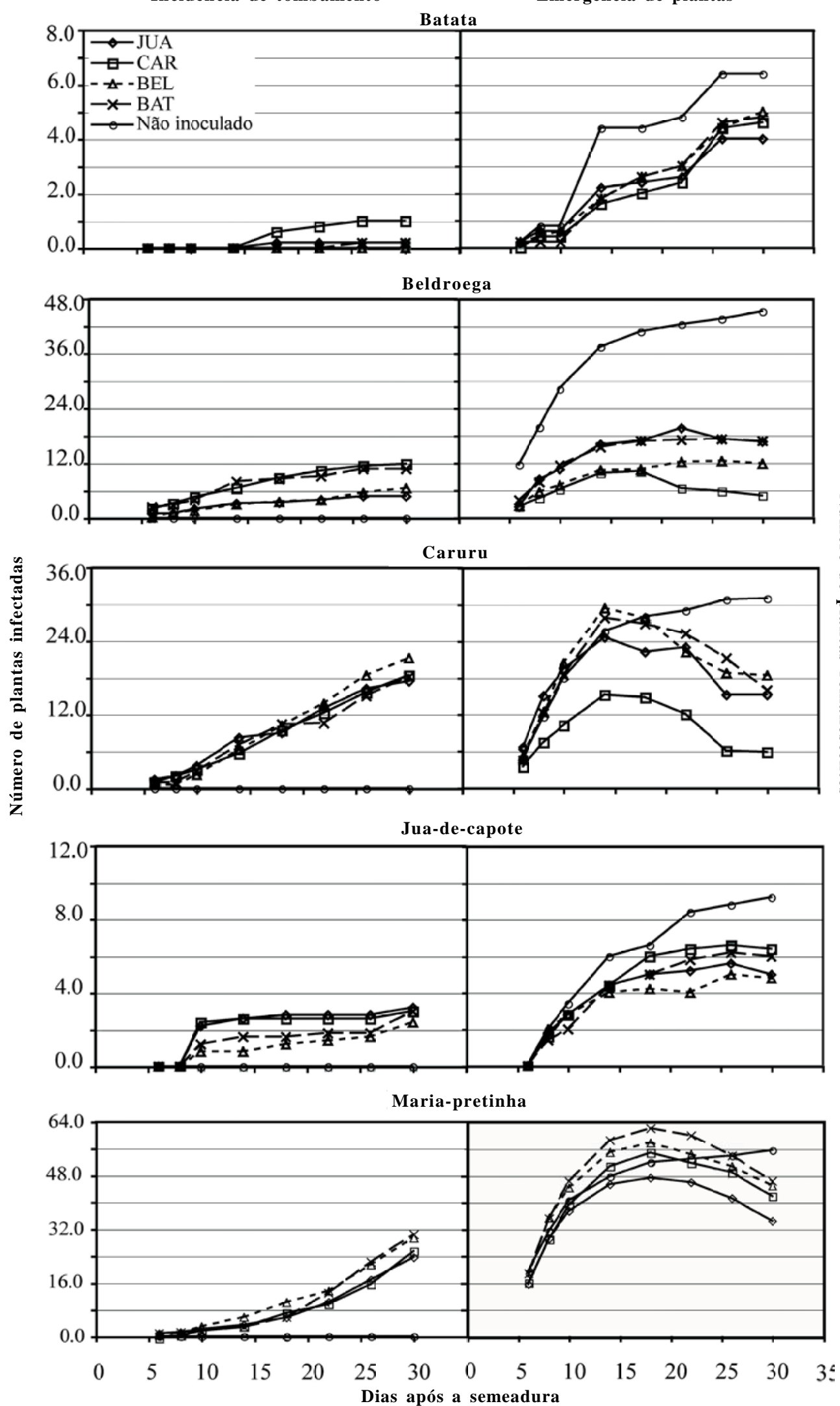

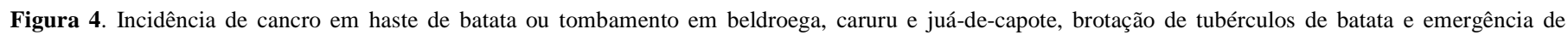

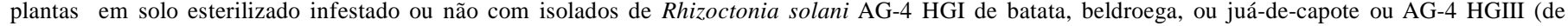

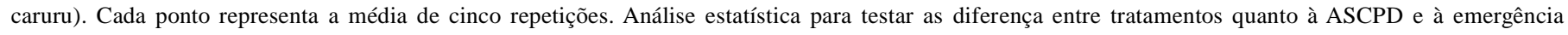
de plantas (Tabela 3). 
Sumarizando os resultados obtidos neste estudo, os isolados de $R$. solani obtidos de batata e de plantas invasoras (beldroega, caruru e juá-de-capote) foram todos caracterizados como AG-4 (HGI para Rhs-BAT, BEL e JUA; HGIII para Rhs-CAR). Com exceção do isolado de beldroega, todos os demais foram patogênicos à batata. Todos os isolados apresentaram patogenicidade cruzada às espécies de plantas invasoras testadas. A associação de $R$. solani AG-4 à plantas invasoras de áreas de cultivo de batata ainda não havia sido relatada no Brasil. A presença de plantas invasoras no campo, durante o cultivo ou após a colheita da batata, pode favorecer a sobrevivência do patógeno em hospedeiros vivos, já que o fungo que infecta a batata também foi patogênico às respectivas plantas invasoras.

Em termos de implicações práticas desta pesquisa, acredita-se que a recomendação da eliminação de plantas invasoras presentes na área de cultivo constitui-se numa medida cultural adicional importante para o controle da incidência de $R$. solani AG-4 na batata. O uso da rotação de culturas como prática isolada poderia não resultar em um controle eficiente do patógeno, já que o mesmo mostrou-se capaz de infectar plantas invasoras como a beldroega, o caruru, o juá-de-capote, e a maria-pretinha, que são freqüentes em áreas de cultivo de batata.

Avanço no controle cultural desta doença de Rhizoctonia na cultura da batata ainda pode ser obtido em estudos subseqüentes buscando-se responder às seguintes perguntas: a) que outras plantas invasoras em áreas de cultivo de batata são suscetíveis à $R$. solani AG-4 e quais são suscetíveis ao AG-3? b) que espécies de plantas invasoras podem hospedar o patógeno como hospedeiros assintomáticos? c) há variação na agressividade de isolados de $R$. solani AG-4 patogênicos a plantas invasoras e à batata? d) qual o grau de influência do manejo das plantas invasoras no controle e ou diminuição do inóculo em áreas de cultivo de batata? e) que tipo de interação há entre plantas invasoras de áreas de batata e microrganismos antagônicos a $R$. solani presentes no solo?

\section{AGRADECIMENTOS}

Os autores agradecem à FAPESP (Fundação de Amparo à Pesquisa do Estado de São Paulo) pela concessão de auxilio à pesquisa (04/ 01793-5) para execução deste estudo.

\section{REFERÊNCIAS BIBLIOGRÁFICAS}

1. Bolkan, H.A.; Ribeiro, W.R.C. Anastomosis groups and pathogenicity of Rhizoctonia solani isolates from Brazil. Plant Disease, St. Paul, v. 69, n. 7, p. 599-601, 1985.

2. Carling, D.E. Grouping in Rhizoctonia solani by hyphal anastomosis reaction. In: Sneh, B.; Jabaji-Hare, S.; Neate, S.; Dijst, G. Rhizoctonia species: taxonomy, molecular biology, ecology, pathology and disease control. Dordrecht: Kluwer Academic, 1996. p. 37-47.

3. Carling, D.E.; Leiner, R.H.; Westphale, P.C. Symptoms, signs, and yield reduction associated with rhizoctonia disease of potato induced by tuberborne inoculum of Rhizoctonia solani AG-3. American potato journal, D.C., v. 66, p. 693-702, 1989.

4. Carling, D.E.; Sumner, D.R. Rhizoctonia. In: Singleton, L.L.; Mihail, J.D.; Rush, C.M. Methods for research on soilborne phytopathogenic fungi. St. Paul: American Phytopathological Society, 1992. p.157-165.

5. Ceresini, P.; Shew, H.D.; James, T.; Vilgalys, R.; Cubeta, M. Phylogeography of the Solanaceae-infecting Basidiomycota fungus Rhizoctonia solani AG-3 based on sequence analysis of two nuclear DNA loci. BMC Evolutionary Biology, v. 7, n. 1, p. 163, 2007.

6. Ceresini, P.C.; Shew, H.D.; Vilgalys, R.; Cubeta, M.A. Genetic diversity of Rhizoctonia solani AG-3 from potato and tobacco in North Carolina. Mycologia, Lancaster, v. 94, n. 3, p. 437-449,
2002.

7. Ceresini, P.C.; Souza, N.L. Caracterização cultural e fisiológica de Rhizoctonia solani GA-4 HGI associado a vagens de amendoinzeiro. Fitopatologia brasileira, Brasília, v. 21, n. 443-454, 1996.

8. Ceresini, P.C.; Souza, N.L. Associação de Rhizoctonia spp. binucleadas e de $R$. solani Kuhn AG-4 HGI e AG-2-2 III B ao feijoeiro (Phaseolus vulgaris L.) no estado de São Paulo. Summa Phytopathologica, Jaboticabal, v. 23, p. 14-23, 1997.

9. Cubeta, M.A.; Vilgalys, R. Rhizoctonia. In: Lederberg, J. Encyclopedia of Microbiology. San Diego: Academic Press, v.4, 2000. p.109-116.

10. Fenille, R.C.; Ciampi, M.B.; Kuramae, E.E.; Souza, N.L. Identification of Rhizoctonia solani associated with soybean in Brazil by rDNA-ITS sequences. Fitopatologia brasileira, Brasília, v. 28, p. 413-419, 2003.

11. Fenille, R.C.; Souza, N.L.; Kuramae, E.E. Characterization of Rhizoctonia solani associated with soybean in Brazil. European journal of plant pathology, Dordrecht, v. 108, p. 783-792, 2002.

12. Gonzalez, D.; Carling, D.E.; Kuninaga, S.; Vilgalys, R.; Cubeta, M.A. Ribosomal DNA systematics of Ceratobasidium and Thanatephorus with Rhizoctonia anamorphs. Mycologia, Lancaster, v. 93, p. 1138-1150, 2001.

13. Gutierrez, W.A.; Shew, H.D.; Melton, T.A. Sources of inoculum and management for Rhizoctonia solani damping-off on tobacco transplants under greenhouse conditions. Plant Disease, St. Paul, v. 81, n. 6, p. 604-606, 1997.

14. Herr, L.J.; Roberts, D.L. Characterization of Rhizoctonia solani populations obtained from sugar beet fields with differing soil textures. Phytopathology, St. Paul, v. 70, p. 476-480, 1980.

15. Hide, G.A.; Hirst, J.M.; Stedman, O.J. Effects of black scurf (Rhizoconia solani) on potatoes. The Annals of applied biology, London, v. 74, p. 139-148, 1973.

16. James, W.C.; Mckenzie, A.R. The effect of tuberborne sclerotia of Rhizoctonia solani Kuhn on the potato crop. American potato journal, D.C., v. 49 p. 296-301, 1972.

17. Kuninaga, S.; Natsuaki, T.; Takeuchi, T.; Yokosawa, R. Sequence variation of the rDNA ITS regions within and between anastomosis groups of Rhizoctonia solani. Current genetics, New York, v. 32, n. 3 p. 237-243 1997.

18. Kuramae, E.E.; Buzeto, A.L.; Ciampi, M.B.; Souza, N.L. Identification of Rhizoctonia solani AG 1-IB in lettuce, AG-4 HG-I in tomato and melon, and AG-4 HGIII in broccoli and spinach, in Brazil. European journal of plant pathology, Dordrecht, v. 109, n. 4, p. 391-395 2003.

19. Madden, L.V.; Hughes, G.; van den Bosch, F. The study of plant disease epidemics St. Paul: The American Phytopathological Society, APS Press, 2007. 421 p.

20. Ogoshi, A.; Ui, T. Specificity in vitamin requirement among anas tomosis groups of Rhizoctonia solani Kühn. Annals of the Phytopathological Society of Japan, Tokyo, v. 45 p. 47-53, 1979.

21. Papavizas, G.C. Colonization and growth of Rhizoctonia solani. In: Parmeter Jr., J.R. Biology and pathology of Rhizoctonia solani. Berkeley: University of California Press, 1970. p.108122 .

22. Posada, D.; Crandall, K.A. MODELTEST: testing the model of DNA substitution. Bioinformatics, London, v. 14, p. 817-818, 1998

23. Richards, B.L. Pathogenicity of Corticium vagum on the potato as affected by soil temperatures. Journal of agricultural research, Washington, v. 21, p. 450-482, 1921.

24. Rosa, D.D.; Kuramae, E.E.; Fenille, R.C.; Souza, N.L. Caracterização citomorforlógica, molecular e patogênica de isolados de Rhizoctonia solani na cultura da batata (Solanum tuberosum). Summa phytopathologica, Botucatu, v. 31, n. 2, 2005.

25. Sanford, G.B. Studies on Rhizoctonia solani Kuhn II. Effect on yield and disease of planting potato sets infested with sclerotia. Scientific agriculture, Ottawa, v. 17, p. 601-611, 1937.

26. Shew, H.D.; Melton, T.A. Target spot of tobacco. Plant disease, St. Paul, v. 79, p. 6-11, 1995. 
27. Sneh, B.; Burpee, L.; Ogoshi, A. Identification of Rhizoctonia species. Saint Paul: The American Phytopathological Society, 1991. $133 \mathrm{p}$

28. Stevens Johnk, J.; Jones, R.K.; Shew, H.D.; Carling, D.E. Characterization of populations of Rhizoctonia solani AG-3 from potato and tobacco. Phytopathology, St. Paul, v. 83, p. 854-858, 1993.
29. Swofford, D.L. PAUP*. Phylogenetic analysis using parsimony (*and other methods), version 4.0b10. Sunderland: Sinauer Associates, 2002.

30. Thompson, J.D.; Gibson, T.J.; Plewniak, F.; Jeanmougin, F.; Higgins, D.G. The ClustalX windows interface: flexible strategies for multiple sequence alignment aided by quality analysis tools. Nuclei acids research, London, v. 25 p. 4876-82, 1997. 